V.O. Brzhezitsky, Y.O. Haran, A.O. Derzhuk, O.R. Protsenko, Y.O. Trotsenko, M.M. Dixit

\title{
ULTIMATE EFFECT OF NON-IDENTITY OF CAPACITIVE ELEMENTS OF HIGH-VOLTAGE ARM ON FREQUENCY CHARACTERISTICS OF VOLTAGE DIVIDER (ANALYTICAL RESEARCH)
}

Purpose. Determination in the analytical form of the maximum limiting influence of the non-identity of the capacitive elements of the
high-voltage arm on the amplitude-frequency characteristic and phase-frequency characteristic of the voltage divider with parallel-
series connection of R-, C-elements of the high-voltage arm. Methodology. Based on the previously developed theory of broadband
voltage dividers with parallel-series connection of R-, C-elements, analytical expressions for amplitude-frequency and phase-
frequency characteristics of the voltage divider are obtained and investigated taking into account the limit case of non-identical
capacitive elements of high-voltage arm. Results. The nature of the dependencies of the frequency characteristics of the broadband
voltage divider on the value of the tolerance of the capacitive elements of the high-voltage arm, the division factor of the voltage
divider in a wide range of frequency changes is determined. Simplified approximating expressions for the maximum values of
frequency characteristics of the voltage divider are proposed and their error is determined. Originality. For the first time in the
analytical form the limiting influence of non-identity of capacitive elements of a high-voltage arm of a voltage divider on its
frequency characteristics is considered. A mathematical model of this influence is constructed and the limit values of frequency
characteristics of the voltage divider are determined. Practical value. It is recommended to introduce into the normative
documentation of broadband voltage dividers the corrected value of the division factor, which allows to significantly reduce the
deviation of the actual value of the division factor of the voltage divider from the normalized value in a wide range of frequency
changes. References 13, tables 2 , figures 3 . Key words: voltage divider, frequency characteristics, analytical expressions, tolerance of capacitive elements, parameters adjustment.

На основі раніме розвинутої теорії иирокосмугових подільників напруги з паралельно-послідовним з'єднанням $R$-, $C$ елементів вперше одержані аналітичні вирази для амплітудно-частотної та фазо-частотної характеристик подільника напруги з урахуванням граничного випадку неідентичності ємнісних елементів високовольтного плеча. Визначений загальний характер залежностей частотних характеристик від значення допуску ємнісних елементів, коефіцієнта ділення подільника напруги в широкому діапазоні зміни частоти. Запропоновані спрощені апроксимуючі вирази для максимальних значень частотних характеристик та визначена їх похибка. Рекомендовано уведення в нормативну документацію иирокосмугових подільників напруги відкоригованого значення коефіцієнта ділення. Бібл. 13 , табл. 2 , рис. 3.

Ключові слова: подільник напруги, частотні характеристики, аналітичні вирази, допуск смнісних елементів, коригування параметрів.

На основе ранее развитой теории широкополосных делителей напряжения с параллельно-последовательным соединением $R$-, C-элементов впервые получены аналитические выражения для амплитудно-частотной и фазо-частотной характеристик делителя напряжения $c$ учетом предельного случая неидентичности ёмкостньх элементов высоковольтного плеча. Определен общий характер зависимостей частотных характеристик от значения допуска ёмкостных элементов, коэффициента деления делителя напряжения в иироком диапазоне изменения частоты. Предложены упрощенные аппроксимирующие выражения для максимальных значений частотных характеристик и определены их погрешности. Рекомендуется введение в нормативную документацию широкополосньх делителей напряжения откорректированного значения коэффициента деления. Библ. 13, табл. 2, рис. 3.

Ключевые слова: делитель напряжения, частотные характеристики, аналитические выражения, допуск ёмкостных элементов, корректировка параметров.

Introduction. Instantaneous voltage values of highvoltage power systems and their changes over time are one of the most important arrays of information about the state and characteristics of such systems (it should be noted that such an array is constantly changing). Decades or more ago, electromagnetic voltage transformers were used (and are still used) to obtain information on high voltage values (there are even DC «voltage transformers»). This is due to the fact that the controls of such systems used relay devices connected to the output circuits of voltage transformers. The operation of such relay devices is focused on tracking steady (or close to them) modes of power systems. The needs of the current stage of power engineering development require the transition to the use of voltage dividers of various types instead of voltage transformers, and here the additional advantage of voltage dividers is the ability to obtain information not only for steady but also for instantaneous transient voltage values (which is important for control systems improvement). However, the transition to the widespread use of voltage dividers requires additional research, including those proposed in this article.

At the National Technical University of Ukraine «Igor Sikorsky Kyiv Polytechnic Institute» systematic studies of high-voltage dividers have been conducted since 1985. The essence of these studies is that for both $\mathrm{AC}$ systems and new DC systems, it is necessary to record instantaneous voltage values, because, for example, for AC systems, transient modes of automatic reconnection, switching and lightning surges, etc. are also important. For DC systems due to the imperfection of rectifiers and inverters, as well as filters, the presence of high voltage ripple (not to mention the importance of recording transients and overvoltages) will be ky, Y.O. Haran, A.O. Derzhuk, O.R. Protsenko, Y.O. Trotsenko, M.M. Dixit 
characterized. Therefore, for both AC and DC systems, it is important to create broadband high-voltage dividers. And in this sense, high-voltage dividers can be unified for both AC and DC systems, which will significantly reduce their cost and increase their availability.

In most cases, the high-voltage arm of broadband voltage dividers consists of a large number of parallelseries connections of $R$-, $C$ - elements, which, in general, are not the same (identical). Taking into account the nonidentity of $R-, C$ - elements of the high-voltage arm is a characteristic feature of the above studies.

This article shows the importance of taking into account the possible non-identity of the capacitive elements of the high-voltage arm of broadband voltage dividers, demonstrates its calculated definition, and provides recommendations for significantly reducing its negative impact, which is an urgent problem.

Review of publications. In the modern concept of «digital substation» there is no need to use traditional relay elements of control systems, as signal processing of voltage and current channels will take place according to the scheme «analog value sensor $\rightarrow$ analog-to-digital converter $\rightarrow$ digital information processing system». In this case, the existing voltage transformers with high cost of insulating and magnetic materials can be replaced by high-voltage broadband voltage dividers [1]. In this regard, recent publications on high-voltage dividers have paid considerable attention to improving the accuracy of mathematical models, the stability of their parameters, taking into account various factors, features of metrological calibration and standardization of voltage dividers. Thus, in [2] it is reported to confirm the change in the division factor of the reference DC voltage divider in the range of $100-1000 \mathrm{kV}$ in the amount of $2.5 \cdot 10^{-6}(2.5 \mathrm{ppm})$. In [3] it is stated about the change of up to $158.4 \mathrm{ppm}$ of the division factor of the voltage divider «500 kV/2 $\mathrm{mA} » \mathrm{DC}$ in an environment with temperature of $35{ }^{\circ} \mathrm{C}$ depending on the duration of operation of the divider in the range of 30-200 minutes. In [4] it is shown that the DC voltage divider up to $1000 \mathrm{kV}$ must have a bandwidth of at least $10 \mathrm{kHz}$. Publications $[5,6]$ are devoted to the creation of real designs of broadband voltage dividers, while in [5] the frequency «response» of the divider according to the substitution scheme is calculated, and in [6] it is established experimentally using an inductive voltage divider. In [7] it is shown that the capacitive «commercial» voltage divider of $22 \mathrm{kV}$ significantly changes its characteristics after 18 hours of continuous operation. In [8] a method of calibration of an industrial $\mathrm{AC}$ voltage divider at the level of $400 \mathrm{kV}$ was developed, and the components of the method uncertainty have the following values: on the division factor $\pm 0.26 \%$; on the phase angle $\pm 3.6 \cdot 10^{-3} \mathrm{rad}$. In [9], the characteristics of the measuring system of the pulse voltage divider with parallel-series connection of $R$-, $C$ - elements of the highvoltage arm, designed to measure the aperiodic switching pulse up to $400 \mathrm{kV}$, are calculated. The considered substitution circuits of different types of high-voltage dividers have shielded parallel-series connections of $R$-, $C$ - elements of a high-voltage arm, «typed», as a rule, with identical values of elements.
An additional advantage of high-voltage dividers is the ability to achieve the unique property of providing a constant value of their amplitude-frequency response in the range from zero to megahertz frequencies, which allows to equally record voltage signals from DC to bursts of short-term pulses [10]. However, this property of voltage dividers can be significantly devalued by the influence of non-identity of real values of $R_{R V^{-}}, C_{R V^{-}}$ elements [10] of their high-voltage arm (deviation of $R_{R V}$, $C_{R V}$ from nominal values $R_{N}, C_{N}$ ).

Since the creation of high-voltage dividers requires a significant number of $R$-, $C$ - elements of the high-voltage arm (from tens to thousands), there is a need to use their less expensive series, which are usually characterized by significant tolerance (normalized deviation of $R_{R V}, C_{R V}$ from $\left.R_{N}, C_{N}\right)$. The tolerance values for resistors $\Delta_{R}=\left(R_{R V}-R_{N}\right) / R_{N}$ and for capacitors $\Delta_{C}=\left(C_{R V}-C_{N}\right) / C_{N}$ differ significantly: for resistors $\Delta_{R}$ has a value of the order of $\pm 0.01( \pm 1 \%)$, and for capacitors $\Delta_{C}$ reaches \pm 0.2 ( $\pm 20 \%$ ).

It matters how $R_{R V}, C_{R V}$ are distributed within the tolerance:

$$
R_{N}\left(1-\Delta_{R}\right) \ldots R_{N}\left(1+\Delta_{R}\right) ; C_{N}\left(1-\Delta_{C}\right) \ldots C_{N}\left(1+\Delta_{C}\right) .
$$

The distribution law of $R_{R V}, C_{R V}$ within the tolerance can be: triangular [11], rectangular, and others (parabolic, etc.). The influence of non-identity of high-voltage arm elements on the characteristics of the voltage divider depends both on the limit values $\Delta_{R}, \Delta_{C}$ for high-voltage arm elements and on the distribution law of $R_{R V}, C_{R V}$ within the respective intervals.

Therefore, the goal of the article is to determine in analytical form the maximum limiting influence of nonidentical capacitive elements of the high-voltage arm on the amplitude-frequency characteristic (frequency response) and phase-frequency characteristic of the voltage divider with parallel-series connection of $R$-, $C$ - elements.

From consideration of the theory of broadband voltage dividers [1] it follows that this case corresponds to the limiting discrete distribution of the elements of the high-voltage arm, when half of its capacitive elements has the value: $C^{\prime}=C_{N}\left(1-\Delta_{C}\right)$, and the other half: $C^{\prime \prime}=C_{N}\left(1+\Delta_{C}\right)$.

In this formulation, the calculation of the frequency characteristics of the high-voltage broadband voltage divider was performed in [12] using separate examples of frequency response and phase-frequency characteristic (PFC) at different values of $\Delta_{C}$, but the general features of the frequency characteristics of broadband voltage dividers were not described.

Research methodology. The substitution circuit of the high-voltage divider for the case considered in [10] is presented in Fig. 1.

The influence of non-identity of $R$-elements of the high-voltage arm is neglected, because usually $\Delta_{R}<<\Delta_{C}$. Below, the index $« C »$ in the notation $\Delta_{C}$ is omitted, therefore $\Delta_{C} \equiv \Delta$, and $R_{1}=R_{2}=\ldots=R_{n}=R$.

According to the general theory of broadband voltage dividers [1], the expressions $A$ for the frequency response and $\varphi$ for PFC of the voltage divider in Fig. 1 can be represented as: 


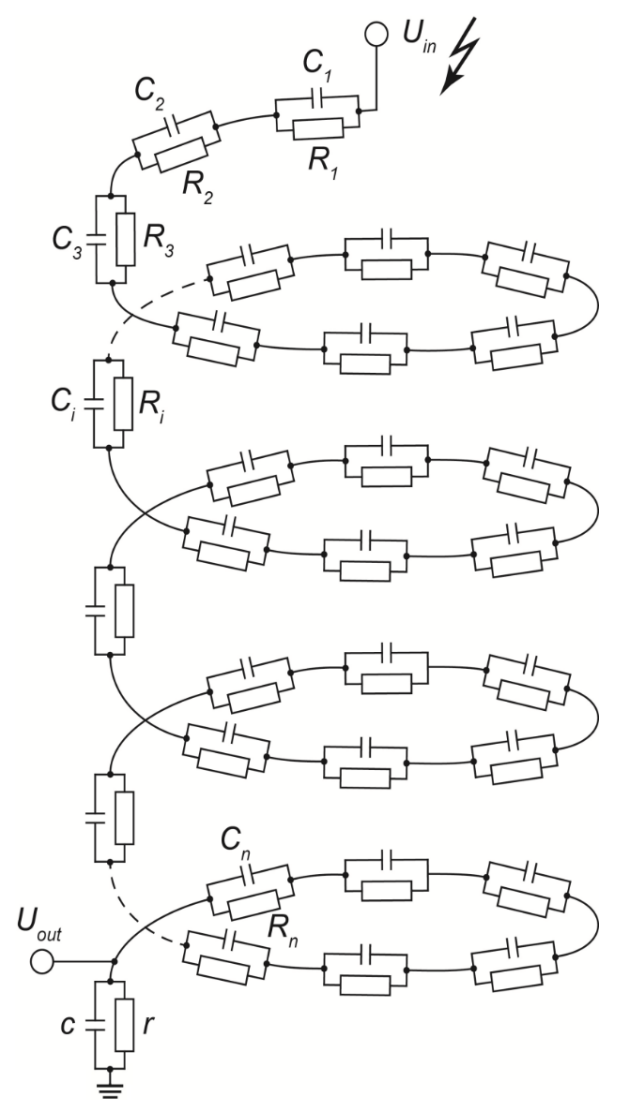

Fig. 1. Substitution circuit of the high-voltage divider voltages with parallel-series connection of $R$-, $C$ - elements of the high-voltage arm

$$
\begin{gathered}
A=\frac{\left|U_{\text {out }}\right|}{\left|U_{\text {in }}\right|}=\frac{1}{K} A^{*}, \\
A^{*}=\sqrt{\frac{1+\gamma^{2}}{\left(1+\frac{K-1}{K} f\right)^{2}+\gamma^{2}\left(1+\frac{K-1}{K} \delta\right)^{2}}}, \\
\varphi=\operatorname{arctg}\left[\frac{(\delta-f) \gamma}{f+\frac{K}{K-1}+\gamma^{2}\left(\delta+\frac{K}{K-1}\right)}\right]
\end{gathered}
$$

where $K$ is the nominal value of the division factor of the voltage divider (in the general case $K>1$ ); $A^{*}$ is the normalized frequency response value; $\gamma=\omega R C_{0}$ is the dimensionless angular frequency $\omega$ parameter; $C_{0}=\frac{1}{n} \sum_{i=1}^{n} C_{i}$ is the average value of the $C$-elements of the high-voltage arm, which in the case under consideration corresponds to $C_{0} \equiv C_{N} ; f, \delta$ are the functions of non-identity of elements; $\alpha=\alpha^{\prime}=-\Delta$, and $\alpha=\alpha^{\prime \prime}=\Delta$, which are determined below:

$$
f=\frac{1}{2} D\left(\alpha^{\prime}\right)+\frac{1}{2} D\left(\alpha^{\prime \prime}\right), \quad \delta=\frac{1}{2} G\left(\alpha^{\prime}\right)+\frac{1}{2} G\left(\alpha^{\prime \prime}\right),
$$

where

$$
D(\alpha)=\frac{\gamma^{2} \alpha^{2}\left(-1+\gamma^{2}(3+2 \alpha)\right)}{\left(1+\gamma^{2}\right)\left[1+\gamma^{2}(1+\alpha)^{2}\right]},
$$

$$
G(\alpha)=\frac{\gamma^{2} \alpha^{2}\left(-3-\alpha+\gamma^{2}(1+\alpha)\right)}{\left(1+\gamma^{2}\right)\left[1+\gamma^{2}(1+\alpha)^{2}\right]} .
$$

Substituting in (3)-(5) values $\alpha^{\prime}=-\Delta, \alpha^{\prime \prime}=\Delta$ we obtain:

$$
\begin{gathered}
2 f=\frac{\gamma^{2} \Delta^{2}\left(-1+\gamma^{2}(3-2 \Delta)\right)}{\left(1+\gamma^{2}\right)\left[1+\gamma^{2}(1-\Delta)^{2}\right]}+\frac{\gamma^{2} \Delta^{2}\left(-1+\gamma^{2}(3+2 \Delta)\right)}{\left(1+\gamma^{2}\right)\left[1+\gamma^{2}(1+\Delta)^{2}\right]}, \\
2 \delta=\frac{\gamma^{2} \Delta^{2}\left(-3+\Delta+\gamma^{2}(1-\Delta)\right)}{\left(1+\gamma^{2}\right)\left[1+\gamma^{2}(1-\Delta)^{2}\right]}+\frac{\gamma^{2} \Delta^{2}\left(-3-\Delta+\gamma^{2}(1+\Delta)\right)}{\left(1+\gamma^{2}\right)\left[1+\gamma^{2}(1+\Delta)^{2}\right]} .
\end{gathered}
$$

In [1], when deriving (1), (2), the well-known relations for the parameters of the low-voltage arm were taken:

$$
r=\frac{n R}{K-1}, \quad c=\frac{C_{0}}{n}(K-1) .
$$

Even with the accepted simplifications (6), (7), the analytical study of the dependencies of $A^{*}, \varphi$ on $\gamma, \Delta, K$ in the general case is impossible. Therefore, we will use the approach of limit values [13], as well as the concept of continuity of functions $A^{*}(\gamma, \Delta, K), \varphi(\gamma, \Delta, K)$, which follows from their physical content.

Limit values of the function $A^{*}(\gamma, \Delta, K)$.

1.1. If $\Delta=0$, then $A^{*} \equiv 1$ for any values $\gamma, K$, because the expressions $f, \delta(6),(7)$ in this case equal to zero.

1.2. If $\gamma=0$, then also $A^{*} \equiv 1$ for any values of $\Delta, K$, which physically corresponds to the generally accepted practice of calibration of broadband voltage dividers at high DC voltage.

1.3. Analyzing (1), (6), (7) we come to the conclusion that we can obtain the boundary expression for $A^{*}$ in the approximation $\gamma^{2} \rightarrow 0$. Indeed, holding in (1), (6), (7) members of the order of the unit, as well as members of the order $\gamma^{2}<<1$, we find

$$
\underset{\gamma \rightarrow 0}{A^{*}}\left(\gamma^{2}\right)=1+\frac{K-1}{K} \Delta^{2} \gamma^{2} \text {. }
$$

Analyzing (8), we conclude that $A^{*}$ for the values of $\gamma<<1$ always increases in the region $A^{*}>1$ in a parabolic dependence on $\gamma$, and in proportion to the square of the tolerance $\Delta^{2}$ and the ratio $(K-1) / K$, i.e., the strongest this dependence is manifested for high-voltage dividers, for which $K>>1$.

1.4. At another threshold $\gamma \rightarrow \infty$ we have:

$$
f=\frac{\Delta^{2}\left(3-\Delta^{2}\right)}{\left(1-\Delta^{2}\right)^{2}} ; \quad \delta=\frac{\Delta^{2}}{1-\Delta^{2}},
$$

and, accordingly:

$$
\underset{\gamma \rightarrow \infty}{A^{*}}=\frac{1}{1+\frac{K-1}{K} \frac{\Delta^{2}}{1-\Delta^{2}}} .
$$

It follows from (10) that in this case always $A^{*}<1$, and the deviation of $A^{*}$ from 1 increases with increasing $K$ and the value of the tolerance $\Delta$ (mainly proportional to $\Delta^{2}$, because for the real tolerance range $0<\Delta<0.2$ contribution the denominator $1-\Delta^{2}$ is $1-1.0417$ ).

1.5. It is of fundamental importance how $A^{*}$ approaches its boundary expression (10): «above» or «below» under the condition $\gamma \rightarrow \infty$. To do this, judging by (1), it suffices to determine the behavior of $\delta$ in the region $\gamma \rightarrow \infty$. The transformation of expression (7) was performed by dividing the numerators and denominators 
of its components by $\gamma^{4}$, and members of the order of units, $1 / \gamma^{2}$ and $1 / \gamma^{4}$, were obtained. Then, holding the members of the order of 1 and $1 / \gamma^{2}$, the following expression was obtained:

$$
\begin{aligned}
& \underset{\gamma \rightarrow \infty}{\delta}\left(\frac{1}{\gamma^{2}}\right)=\frac{\Delta^{2}}{1-\Delta^{2}}-\frac{\Delta^{2}}{2 \gamma^{2}} \times \\
& \times\left[\frac{3-\Delta}{(1-\Delta)^{2}}+\frac{1+(1-\Delta)^{2}}{(1-\Delta)^{3}}+\frac{3+\Delta}{(1+\Delta)^{2}}+\frac{1+(1+\Delta)^{2}}{(1+\Delta)^{3}}\right]
\end{aligned}
$$

The expression in square brackets for $0<\Delta<0.2$ is always greater than zero. Therefore, $\delta$ under the condition $\gamma \rightarrow \infty$ approaches its limit value $\Delta^{2} /\left(1-\Delta^{2}\right)$ from below. Accordingly, the function $A^{*}(\gamma)$ approaches its limit value (10) always from above.

1.6. Given that depending on $\gamma$ there will be a transition from the values $A^{*}>1$ to the values $A^{*}<1$, it will be useful to find out the value $A^{*}$ at $\gamma=1$. For this case, the substitution $\gamma=1$ in (1), (6), (7) after performing the reductions gives:

$$
A^{*}(1)=\sqrt{1-2 \frac{\Delta^{4}}{4+\Delta^{4}} \frac{K-1}{K}\left(1-\frac{K-1}{2 K}\right)} .
$$

Analysis of (12), as well as of (8)-(11), under the condition $\Delta=0$ confirms the value $A^{*} \equiv 1$. Since in the field of practical interest there is $0<\Delta<0.2$ and then $\Delta^{4} /\left(4+\Delta^{4}\right)<<1$, expression (12) can be represented as

$$
A^{*}(1) \cong 1+\frac{\Delta^{4}}{4+\Delta^{4}} \frac{K-1}{K}\left(1-\frac{K-1}{2 K}\right) .
$$

For the values of $K>>1$ and $\Delta=0.2$, the addition to the unit in (13) is 0.0002 . That is, all dependencies $A^{*}(\gamma)$ for $0<\Delta<0.2$ will practically pass through the point $A^{*}(1)=1$.

1.7. Investigation of $A *$ in the range $0<\gamma<1$. From all previous features, in this range the maximum of the function should be. To find it, it is necessary to equate to zero the derivative $d A^{*} / d \gamma=0$, and from this condition to determine the value $\gamma_{\max }$, the substitution of which in (1), (6), (7) will allow to obtain the desired value $A_{\max }$. Due to the complex dependence of $A^{*}$ on the input values, which practically makes it impossible to perform these operations in analytical form, the computer code is used to find $A_{\max }^{*}\left(\gamma_{\max }\right)$.

The SMath Studio computer code derived the functional dependence of $A^{*}$ on $\gamma$, after which, using the mathematical modules of this code, we found the value $\gamma_{\max }$ for the extremum point and the extremum value $A_{\max }^{*}$ of this function for different $\Delta$ and $K$ (by iterative calculation in the program cycle).

Table 1 shows the obtained results of calculations of $A_{\max }^{*}, \gamma_{\max }$ for values $\Delta=0.01 ; 0.02 ; \ldots 0.19 ; 0.20$ and

\begin{tabular}{|c|c|c|c|c|c|c|c|c|}
\hline Value & \multicolumn{2}{|c|}{$K=10$} & \multicolumn{2}{|c|}{$K=100$} & \multicolumn{2}{|c|}{$K=1000$} & \multicolumn{2}{|c|}{$K=10000$} \\
\hline$\Delta$, p.u. & $\gamma_{\max }$ & $A_{\max }^{*}$ & $\gamma_{\max }$ & $A_{\max }^{*}$ & $\gamma_{\max }$ & $A_{\max }^{*}$ & $\gamma_{\max }$ & $A_{\max }^{*}$ \\
\hline 0,01 & 0,577361 & 1,0000112502 & 0,577360 & 1,0000123752 & 0,577360 & 1,0000124877 & 0,577360 & 1,0000124990 \\
\hline 0,02 & 0,577393 & 1,0000450035 & 0,577389 & 1,0000495037 & 0,577389 & 1,0000499537 & 0,577389 & 1,0000499988 \\
\hline 0,03 & 0,577446 & 1,0001012677 & 0,577438 & 1,0001113939 & 0,577437 & 1,000112406 & 0,577437 & 1,0001125077 \\
\hline 0,04 & 0,577520 & 1,0001800558 & 0,577506 & 1,0001980596 & 0,577504 & 1,0001998600 & 0,577504 & 1,0002000400 \\
\hline 0,05 & 0,577615 & 1,0002813863 & 0,577593 & 1,0003095206 & 0,577591 & 1,0003123340 & 0,577591 & 1,0003126153 \\
\hline 0,06 & 0,577732 & 1,0004052827 & 0,577700 & 1,0004458019 & 0,577697 & 1,0004498538 & 0,577697 & 1,0004502590 \\
\hline 0,07 & 0,577870 & 1,0005517740 & 0,577827 & 1,0006069345 & 0,577823 & 1,0006124504 & 0,577822 & 1,0006130020 \\
\hline 0,08 & 0,578029 & 1,0007208942 & 0,577973 & 1,0007929549 & 0,577968 & 1,0008001606 & 0,577967 & 1,0008008812 \\
\hline 0,09 & 0,578210 & 1,0009126829 & 0,578139 & 1,0010039051 & 0,578132 & 1,0010130268 & 0,578131 & 1,0010139390 \\
\hline 0,1 & 0,578412 & 1,0011271850 & 0,578325 & 1,001239833 & 0,578316 & 1,0012510971 & 0,578315 & 1,0012522235 \\
\hline 0,11 & 0,578636 & 1,0013644507 & 0,578530 & 1,0015007923 & 0,578519 & 1,0015144254 & 0,578518 & 1,0015157887 \\
\hline 0,12 & 0,578881 & 1,0016245356 & 0,578755 & 1,0017868422 & 0,578742 & 1,0018030714 & 0,578741 & 1,0018046943 \\
\hline 0,13 & 0,579148 & 1,0019075010 & 0,579000 & 1,0020980480 & 0,578985 & 1,0021171007 & 0,578984 & 1,0021190059 \\
\hline 0,14 & 0,579437 & 1,0022134135 & 0,579265 & 1,0024344807 & 0,579247 & 1,002456585 & 0,579246 & 1,0024587951 \\
\hline 0,15 & 0,579748 & 1,0025423452 & 0,579550 & 1,0027962172 & 0,579530 & 1,0028216008 & 0,579528 & 1,0028241391 \\
\hline 0,16 & 0,580081 & 1,0028943741 & 0,579855 & 1,00318334 & 0,579832 & 1,0032122322 & 0,579830 & 1,0032151214 \\
\hline 0,17 & 0,580436 & 1,0032695835 & 0,580180 & 1,0035959389 & 0,580154 & 1,0036285684 & 0,580152 & 1,0036318313 \\
\hline 0,18 & 0,580813 & 1,0036680628 & 0,580525 & 1,0040341078 & 0,580497 & 1,0040707048 & 0,580494 & 1,0040743644 \\
\hline 0,19 & 0,581213 & 1,0040899069 & 0,580891 & 1,0044979482 & 0,580859 & 1,0045387429 & 0,580856 & 1,0045428223 \\
\hline 0,2 & 0,581635 & 1,0045352169 & 0,581278 & 1,0049875672 & 0,581242 & 1,0050327906 & 0,581239 & 1,0050373128 \\
\hline
\end{tabular}
values $K=10 ; 100 ; 1000 ; 10000$.

Table 1

Results of calculations of values $A_{\max }^{*}$ (p.u.), $\gamma_{\max }$ (p.u.) 
Data processing from Table 1 allows to propose a simplified expression for $A_{\max }^{*}$ in the form:

$$
A_{\max }^{*}=1+0,1255 \frac{K-1}{K} \Delta^{2} \text {. }
$$

The error is only the term of the right part (14) in relation to the corresponding data in Table 1 does not exceed $\pm 0.4 \%$ in absolute value, which can be considered quite acceptable.
Figure 2 shows graphs of dependencies $A^{*}(\gamma)$ calculated by (1), (6), (7) for values of parameters: $\Delta=0.05 ; 0.2 ; K=10 ; 10^{4}$, which explain the results obtained. To track the complete change of the curves $A^{*}(\gamma)$, the range of change in $\gamma$ (on the abscissa axis) is presented on a logarithmic scale (from $\gamma=0.001$ to $\gamma=1000)$.

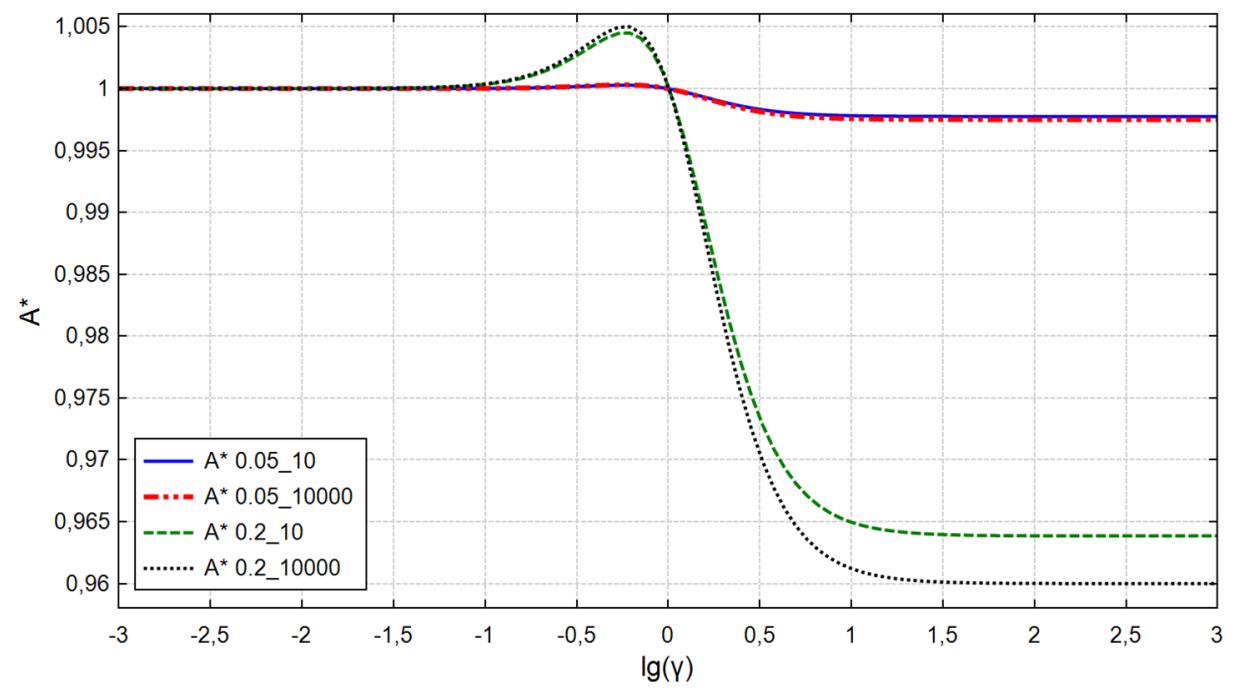

Fig. 2. Calculated dependencies $A^{*}(\gamma)$ by (1), (6), (7) for parameter values: $\Delta=0.05 ; \Delta=0.2 ; K=10 ; K=10^{4}$

Limit values of the function $\varphi(\gamma, \Delta, K)$. Both for the value $\gamma \rightarrow 0$ and for $\gamma \rightarrow \infty$, the function $\varphi$ has a limit value $\varphi \rightarrow 0$, which physically corresponds to the idealized ohmic (in the first case) and idealized capacitive (in the second case) voltage divider.

The expansion of the function $\varphi(2)$ by the powers of the small parameter $\gamma$ under the condition $\gamma \rightarrow 0$ determines the expression

$$
\underset{\gamma \rightarrow 0}{\varphi}(\gamma)=-2 \frac{K-1}{K} \Delta^{2} \gamma^{3}
$$

and the value $\varphi$ in (15) is obtained in radians.

At another limit value $\gamma \rightarrow \infty$, the expansion of $\varphi$ (2) by the powers of the small parameter $1 / \gamma$ gives the expression

$$
\underset{\gamma \rightarrow \infty}{\varphi}(\gamma)=-2 \frac{K-1}{K} \cdot \frac{\Delta^{2}}{\gamma} \Psi(\Delta, K),
$$

where the correction function is of the order of unit

$$
\Psi=\left(1-2 \frac{\Delta^{2}}{K}-\frac{K-2}{K} \Delta^{4}\right)^{-1}
$$

Maximum value $\Psi$ at $\Delta=0.2 ; K=10$ is 1.009367 , hence for the terms of consideration $1<\Psi<1.009367$.

Similarly to item 1.7 , the values $\varphi_{\text {min }}^{\prime}(2)$, in angular minutes, and the corresponding values $\gamma^{\prime}$ (p.u.) were found using the SMath Studio computer code for the parameters $\Delta=0.01 ; 0.02 ; \ldots 0.19 ; 0.2$ and values $K=10$; $100 ; 1000 ; 10000$, presented in Table 2.

Table 2

Results of calculations of values $\varphi_{\text {min }}^{\prime}$ (angular minutes), $\gamma^{\prime}$ (p.u.)

\begin{tabular}{|c|c|c|c|c|c|c|c|c|}
\hline Value & \multicolumn{2}{|c|}{$K=10$} & \multicolumn{2}{c|}{$K=100$} & \multicolumn{2}{c|}{$K=1000$} & \multicolumn{2}{c|}{$K=10000$} \\
\hline$\Delta$, p.u. & $\gamma^{\prime}$ & $\varphi_{\text {min }}^{\prime}$ & $\gamma^{\prime}$ & $\varphi_{\text {min }}^{\prime}$ & $\gamma^{\prime}$ & $\varphi_{\text {min }}^{\prime}$ & $\gamma^{\prime}$ & $\varphi_{\text {min }}^{\prime}$ \\
\hline 0,01 & 1,73214 & $-0,200968$ & 1,73213 & $-0,221064$ & 1,73213 & $-0,223073$ & 1,73213 & $-0,223274$ \\
\hline 0,02 & 1,73243 & $-0,80397$ & 1,7324 & $-0,884355$ & 1,73239 & $-0,892394$ & 1,73239 & $-0,893197$ \\
\hline 0,03 & 1,7329 & $-1,80931$ & 1,73283 & $-1,99018$ & 1,73283 & $-2,00826$ & 1,73283 & $-2,01007$ \\
\hline 0,04 & 1,73357 & $-3,21747$ & 1,73345 & $-3,53903$ & 1,73343 & $-3,57118$ & 1,73343 & $-3,5744$ \\
\hline 0,05 & 1,73443 & $-5,02917$ & 1,73424 & $-5,53162$ & 1,73422 & $-5,58186$ & 1,73422 & $-5,58689$ \\
\hline 0,06 & 1,73549 & $-7,2453$ & 1,7352 & $-7,96886$ & 1,73518 & $-8,04121$ & 1,73517 & $-8,04844$ \\
\hline 0,07 & 1,73673 & $-9,86697$ & 1,73635 & $-10,8519$ & 1,73631 & $-10,9503$ & 1,73631 & $-10,9602$ \\
\hline 0,08 & 1,73817 & $-12,8955$ & 1,73767 & $-14,1819$ & 1,73762 & $-14,3106$ & 1,73762 & $-14,3234$ \\
\hline 0,09 & 1,73981 & $-16,3323$ & 1,73918 & $-17,9606$ & 1,73911 & $-18,1234$ & 1,73911 & $-18,1397$ \\
\hline 0,1 & 1,74165 & $-20,1793$ & 1,74086 & $-22,1897$ & 1,74078 & $-22,3906$ & 1,74077 & $-22,4107$ \\
\hline
\end{tabular}


Table 2 (continued)

\begin{tabular}{|c|c|c|c|c|c|c|c|c|}
\hline Value & \multicolumn{2}{|c|}{$K=10$} & \multicolumn{2}{c|}{$K=100$} & \multicolumn{2}{c|}{$K=1000$} & \multicolumn{2}{c|}{$K=10000$} \\
\hline$\Delta$, p.u. & $\gamma^{\prime}$ & $\varphi_{\min }^{\prime}$ & $\gamma^{\prime}$ & $\varphi_{\text {min }}^{\prime}$ & $\gamma^{\prime}$ & $\varphi_{\text {min }}^{\prime}$ & $\gamma^{\prime}$ & $\varphi_{\text {min }}^{\prime}$ \\
\hline 0,11 & 1,74368 & $-24,4383$ & 1,74273 & $-26,871$ & 1,74263 & $-27,1142$ & 1,74262 & $-27,1385$ \\
\hline 0,12 & 1,74592 & $-29,1114$ & 1,74478 & $-32,0069$ & 1,74467 & $-32,2962$ & 1,74466 & $-32,3252$ \\
\hline 0,13 & 1,74836 & $-34,2011$ & 1,74702 & $-37,5995$ & 1,74689 & $-37,9392$ & 1,74687 & $-37,9731$ \\
\hline 0,14 & 1,751 & $-39,71$ & 1,74945 & $-43,6517$ & 1,74929 & $-44,0456$ & 1,74928 & $-44,085$ \\
\hline 0,15 & 1,75386 & $-45,6408$ & 1,75207 & $-50,1662$ & 1,75189 & $-50,6183$ & 1,75187 & $-50,6636$ \\
\hline 0,16 & 1,75692 & $-51,9966$ & 1,75488 & $-57,1461$ & 1,75468 & $-57,6605$ & 1,75466 & $-57,712$ \\
\hline 0,17 & 1,7602 & $-58,7808$ & 1,75789 & $-64,5947$ & 1,75766 & $-65,1754$ & 1,75764 & $-65,2335$ \\
\hline 0,18 & 1,76369 & $-65,9969$ & 1,7611 & $-72,5155$ & 1,76084 & $-73,1666$ & 1,76081 & $-73,2317$ \\
\hline 0,19 & 1,76741 & $-73,6486$ & 1,76451 & $-80,9124$ & 1,76422 & $-81,6378$ & 1,76419 & $-81,7103$ \\
\hline 0,2 & 1,77135 & $-81,74$ & 1,76812 & $-89,7895$ & 1,7678 & $-90,5932$ & 1,76777 & $-90,6735$ \\
\hline
\end{tabular}

Data processing from Table 2 allows to propose a simplified expression for $\varphi_{\text {min }}^{\prime}$ in the form:

$$
\varphi_{\min }^{\prime}=-2252 \frac{K-1}{K} \Delta^{2}
$$

The error (17) in relation to the corresponding data from Table 2 does not exceed $\pm 0.85 \%$ in absolute value, which can be considered acceptable.
Figure 3 shows the graphs of the dependencies $\varphi^{\prime}(\gamma)$, calculated by (2), (6), (7) for the values of the parameters: $\Delta=0.05 ; 0.20 ; K=10 ; 10^{4}$, explaining the results obtained. To track the complete change of the curves $\varphi^{\prime}(\gamma)$ the range of change in $\gamma$ (on the abscissa axis) is presented on a logarithmic scale (from $\gamma=0.001$ to $\gamma=1000$ ).

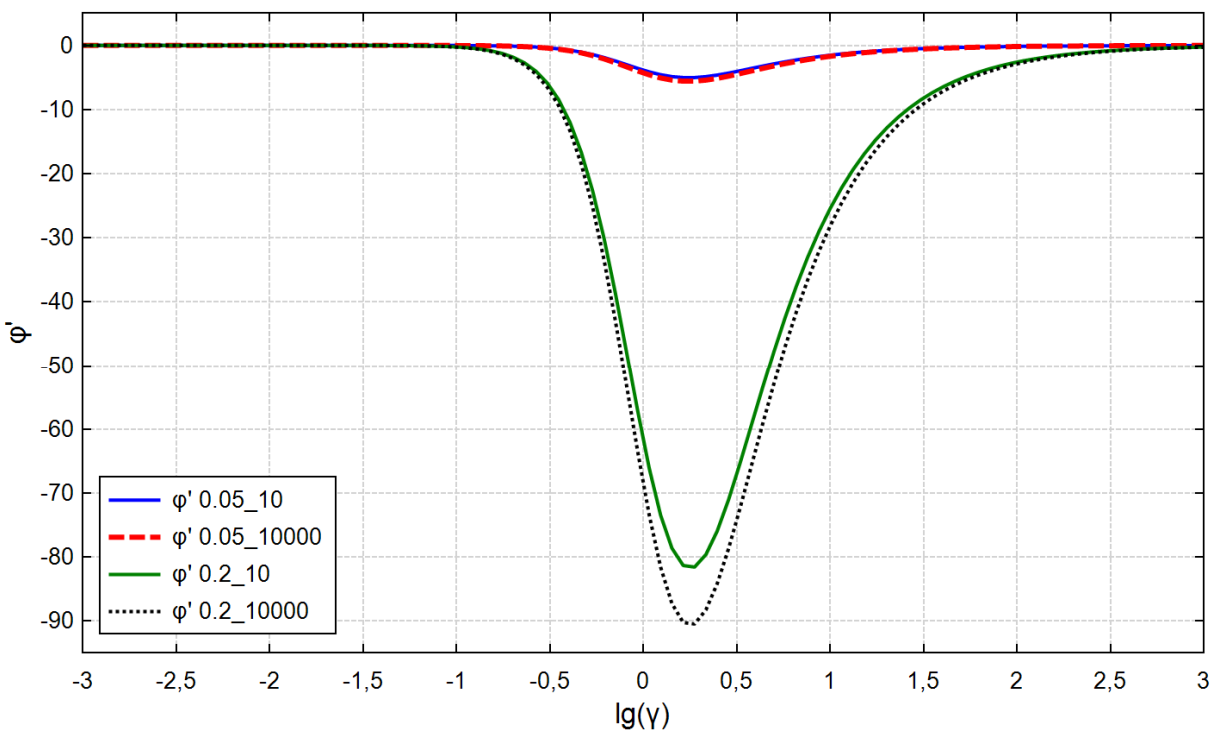

Fig. 3. Calculated dependencies $\varphi^{\prime}$ (angular minutes) on $\gamma$ (p.u.) by (2), (6), (7) for parameter values: $\Delta=0,05 ; \Delta=0,2 ; K=10 ; K=10^{4}$

Discussion of the results obtained. For the first time in general form, the general features of the frequency characteristics of high-voltage broadband voltage dividers with parallel-series connection of $R-, C$ - elements of the high-voltage arm, taking into account the non-identity of its capacitive components are discussed.

For the first time, the limiting influence of the nonidentity of the capacitive elements of the high-voltage arm on the frequency response and PFC of the voltage divider was quantified and its essential importance was shown.

For the first time, simplified and, at the same time, sufficiently accurate expressions for the limit values of their frequency characteristics are proposed for the range of division factors of broadband voltage dividers $K \geq 10$. For the range of division factors of voltage dividers $1<K<10$ it is necessary to conduct additional research.
To reduce the deviations of the frequency response (from the normalized value) of the broadband voltage divider depending on the frequency, it may be recommended to use its adjusted value $A_{c o r}^{*}=\frac{1}{2}\left(A_{\max }^{*}+\underset{\gamma \rightarrow \infty}{A^{*}}\right)$ and the corresponding adjusted value of the division factor of the voltage divider $K_{c o r}=K / A_{c o r}^{*}$, which can be entered in its passport.

To reduce the deviations of the PFC (from the normalized value) of the voltage divider depending on the frequency, it is recommended to use its adjusted value $\varphi_{\text {cor }}^{\prime}=0.5 \cdot \varphi_{\text {min }}^{\prime}$, which can be entered in the passport of the voltage divider for the range $\gamma>0$.

Comparison of the obtained results with the data of publications [2-9] shows that the influence of non-identity 
of capacitive elements of high-voltage arm of voltage dividers on their characteristics is significant along with other influencing factors and, therefore, should be taken into account in theory and practice of voltage dividers.

\section{Conclusions.}

For the first time in the analytical form the frequency characteristics of a broadband voltage divider are studied taking into account the ultimate influence of non-identity of capacitive elements of its high-voltage arm, which allows to clearly predict the limits of change of amplitudefrequency and phase-frequency characteristics of a voltage divider depending on the tolerance of its constituent elements.

To reduce deviations from the normalized values of the amplitude-frequency and phase-frequency characteristics of the broadband voltage divider depending on the frequency, it is recommended to use their adjusted values, which can be added in the passport and regulatory documentation of the voltage divider.

The obtained results allow to orient the predicted value of the tolerance of capacitive elements of the highvoltage arm when choosing broadband high-voltage voltage dividers, as well as during their development and manufacture.

Prospects for further development in this direction are associated with the use of different laws of distribution of actual values $R_{R V}, C_{R V}$ within their tolerances, including asymmetric types of distributions.

Conflict of interest. The authors of the article declare no conflict of interest.

\section{Anokhin Y.L., Brzhezytskyi V.O., Haran Ya.O.,} Masliuchenko I.M., Protsenko O.P., Trotsenko Ye.O. Application of high voltage dividers for power quality indices measurement. Electrical Engineering \& Electromechanics, 2017, no. 6, pp. 53-59. doi: https://doi.org/10.20998/2074272x.2017.6.08.

2. Li D., Liu K., Lei M., Zhou F., Yue C., Yu J. Study on the ratio change measurement of $1000 \mathrm{kV}$ HVDC divider based on improved DC voltage summation method. High Voltage, 2020, vol. 5, no. 2 , pp. 202-208. doi: https://doi.org/10.1049/hve.2019.0127.

3. Fang Z., Luo Y., Zhai S., Qian B., Liao Y., Lan L., Wang D. Temperature rise characteristics and error analysis of a DC voltage divider. Energies, 2021, vol. 14, no. 7, p. 1914. doi https://doi.org/10.3390/en14071914.

4. Alf-Peter E., Hällström J., Bergman A. Optimization of the design of a wideband $1000 \mathrm{kV}$ resistive reference divider. XVII International Symposium on High Voltage Engineering, Hannover, Germany, August 22-26, 2011. Available at: http://vlabs.iitkgp.ac.in/vhvlab/html/pages/CD/topics a-h/H013-ELG-F.pdf (accessed 22 June 2020).

5. Khamlichi A., Rovira J. The Design and characterization of a prototype wideband voltage sensor based on a resistive divider. Sensors, 2017, vol. 17, no. 11, p. 2657. doi: https://doi.org/10.3390/s17112657.
6. Slomovitz D., Trigo L., Faverio C., Kyriazis G.A. Advance in the development of wideband resistive voltage dividers. Journal of Physics: Conference Series, 2021, vol. 1826, no. 1, p. 012083. doi: https://doi.org/10.1088/1742-6596/1826/1/012083.

7. Hrbac R., Kolar V., Bartlomiejczyk M., Mlcak T., Orsag P., Vanc J. A development of a capacitive voltage divider for high voltage measurement as part of a combined current and voltage sensor. Elektronika ir Elektrotechnika, 2020, vol. 26, no. 4, pp. 25-31. doi: https://doi.org/10.5755/j01.eie.26.4.25888.

8. Xu D., Zhang W., Wang N., Wang G., Xu G. The power frequency voltage divider calibration device and its uncertainty. Energy Reports, 2020, vol. 6, pp. 380-384. doi: https://doi.org/10.1016/j.egyr.2019.11.091.

9. Havunen J., Hällström J. Reference switching impulse voltage measuring system based on correcting the voltage divider response with software. IEEE Transactions on Instrumentation and Measurement, 2021, vol. 70, pp. 1-8. art. no. 1006008. doi: https://doi.org/10.1109/tim.2021.3063753.

10. Brzhezitsky V., Trotsenko Y., Haran Y. Optimization of amplitude-frequency characteristic of broadband voltage divider intended for measurement of power quality parameters. Technology audit and production reserves, 2020, vol. 3 , no. 1 (53), pp. 35-39. doi: https://doi.org/10.15587/27065448.2020.205132.

11. Brzhezitsky V., Haran Y., Derzhuk A., Trotsenko Y., Protsenko $\mathrm{O}$. Amplitude-frequency characteristic of broadband voltage divider with ultimate adjustment of its low-voltage arm. 2020 IEEE 7th International Conference on Energy Smart Systems (ESS), 2020, pp. 111-115, doi: https://doi.org/10.1109/ess50319.2020.9160094.

12. Brzhezytskyi V.O., Masliuchenko I.M., Laposha M.Y. Maximum influence of nonidentical R- and C-elements of a highvoltage divider on its frequency characteristics. Power Engineering: economics, technique, ecology, 2017, no. 1, pp. 70-76. (Ukr). doi: https://doi.org/10.20535/1813-5420.1.2017.102824.

13. Korn G.A., Korn T.M. Mathematical handbook for Scientists and engineers. Dover Publications, 2000. 1151 p.

Received 28.05.2021

Accepted 30.06.2021

Published 27.08.2021

V.O. Brzhezitsky ${ }^{1}$, Doctor of Technical Science, Professor,

Y.O. Haran $^{1}, \mathrm{PhD}$,

A.O. Derzhuk ${ }^{1}$, Postgraduate Student,

O.R. Protsenko ${ }^{1}$, PhD, Associate Professor,

Y.O. Trotsenko ${ }^{1}, P h D$, Associate Professor,

M.M. Dixit ${ }^{2}$

${ }^{1}$ National Technical University of Ukraine «Igor Sikorsky Kyiv

Polytechnic Institute»,

37, Prospect Peremohy, Kyiv-56, 03056, Ukraine,

e-mail: v.brzhezitskiy@ukr.net (Corresponding author)

${ }^{2}$ Vishwaniketan Institute of Management Entrepreneurship

and Engineering Technology,

Survey No. 52, Kumbhivali, Tal, Khalapur, Maharashtra, 410202, India,

e-mail: mandardixit78@gmail.com

\section{How to cite this article:}

Brzhezitsky V.O., Haran Y.O., Derzhuk A.O., Protsenko O.R., Trotsenko Y.O., Dixit M.M. Ultimate effect of non-identity of capacitive elements of high-voltage arm on frequency characteristics of voltage divider (analytical research). Electrical Engineering \& Electromechanics, 2021, no. 4, pp. 46-52. doi: https://doi.org/10.20998/2074-272X.2021.4.06. 